\title{
COMPUTER AIDED DESIGN OF SOIL MOISTURE SENSOR AND ITS MEASUREMENTS FOR AGRICULTURAL WATER RESOURCES MANAGEMENT
}

\author{
Khaja Syed Shahul Hameed S. ${ }^{1}$, Agarwala A.K. ${ }^{2}$ \\ ${ }^{1,2}$ Instrument Design and Development Centre, Indian Institute of Technology Delhi, New Delhi, India \\ Email: 1iitd2005@gmail.com
}

\begin{abstract}
Water being the principal potential source of enlivening the plants on earth and without it, it is the end for the life of living beings on earth. Though about two third of the world is of water but there is a scarcity of water for drinking for living beings as well as for plant watering. Inefficient watering of plants making water table fall and in many zones world wide becoming drought prone resulting in famine, mal-nutrition and suicides. Farmers being largely unscientific and unskilled mostly in developing countries using water inappropriately thereby agricultural yield is below its optimum level as well as land becoming saline due to washing of excess pesticides, fertilizers and water logging and becoming unfit for further farming. Hence it is proposed in this paper a novel approach to determine the efficient water requirement of agricultural fields for farming in a most scientific and cost effective manner and to design a ultra low cost moisture sensor using computer and thereby to manage the water resources more appropriately in agricultural farms for the plants irrigation and its results are presented.
\end{abstract}

Key words: Agricultural water resources, GHGs emission, irrigation automation, low cost sensor, soil moisture sensor

\section{INTRODUCTION}

The water being the precious but most mismanaged resource on earth and continuous improper usage can lead to the loss of the global living beings viz, plant, animal, human beings and may lead to an end of life in this world. Considering the prime importance and its utility, its proposed to optimize the water usage for irrigation purposes as animals and human beings depend on agricultural produce for their survival.

Though water is a renewable resource but in reality the availability of water for the society is limited and hence, there is a tremendous pressure on the available water resources due to increasing population and growing water consumption for industries. In most of the cities, people do not get an adequate amount of water to meet their daily needs and supplies are highly uncertain. Quality of drinking water is often poor, often contaminated during rainy season, leading to high incidence of water borne diseases. The metropolitan cities have inadequate drainage networks which get often choked resulting in water logging, disruption of traffic, and health hazards. Owing to indiscriminate over use many rivers have died and many others have become sewers because municipal and industrial waste is dumped in them with little or no treatment. Hence in future, more water will be required for domestic, irrigation, industrial, hydropower, and other uses. The need for better management of available water resources to meet the basic necessities for growing population and industrial activities and to provide hazard free water for the society has never been more important and importantly, many developing countries are facing similar problems to varying degrees.
Consider India and its well known that more than $70 \%$ of Indian farmers are illiterate and hold land much less than 1-2 hectares. For these marginal farmers Government is providing them with free electricity, subsidized fertilizer and farm loans. The farmers are not knowing the scientific farming and financially very poor and use free electricity to pump water from the ground and as a result water table is rapidly falling in many places across India. In order to develop an optimum technologies for use in the fields by these illiterate farmers and to save the soil from becoming water logged and saline, an effort was made to develop a gadget which even an illiterate farmer can use at the same time it has to be cost effective to be used in fields.

The total geographical area of India is about 329Mha and about 97 Mha agricultural fields are being irrigated by ground and surface water. The principal food crops are rice, wheat. Most of the natives eat rice or wheat or both as food requirement. The total area under cultivation of rice is about 44 Mha and wheat is 27 Mha with wheat and rice being rotational crops in most parts of India. The average yield of rice is $3.26 t /$ ha and wheat is $2.4 t / h a$ and at these yield levels the farmer is unable to recover the cost incurred apart from the feeding and survival needs of the family. This results increase in debt as the minimum support price(MSP) for his produce is being fixed by the government and the sustenance of his family on this small acreage of land holdings at the existing yield levels is becoming highly unviable.

The total installed capacity of power in India is $132,110 \mathrm{MW}$ of which hydro power is $34654 \mathrm{MW}$ representing about $26 \%$, thermal power is $85575 \mathrm{MW}$ representing about $65 \%$, nuclear power reactor is 
4120MW representing about $3 \%$ of the total installed capacity. The per capita power consumption is about $600 \mathrm{KWH}$ per year. Of the total power generated, about $30 \%$ of electricity is consumed by agricultural sector alone, where due to free power scheme for farmers by many state governments, the most inefficient and unrated pumps, with dismal efficiency which are otherwise cheaper than power saving pumps are used for pumping the ground water, resulting in falling water table in places and about 108Mha of land has become drought prone across India resulting in farmer committing suicides.

The agricultural power tariff is abysmally low in many states and linked to the connected load and not to the actual consumption of electric power for big farmers and absolutely free for small and marginal farmers so there is little incentive for farmer to be an efficient electricity consumer. Automated irrigation system for optimizing the water usage in fields for crops viz,. wheat, rice in India is the need of the hour to save agriculture, electricity can be saved apart from ground water and also environmental emissions from power plants such as $\mathrm{CO}, \mathrm{CO}_{2}$, Sulphur compounds resulting in climate changes can be avoided. So the sensor has been designed to optimize soil moisture at the required level for different crops thereby huge savings on electricity, environmental and climate effects.

Soil moisture measurements are vital for the irrigation scheduling as it can help in providing adequate quantity of requisite water to the plants for their photosynthesis and survival needs. Ultimately all living beings such as humans, animals feed on agricultural crop produce for their feeding and energy requirements and as such the plants are the vital backbone of the existence of life on earth. As its certain that no plants can survive without water the principal source through which nutrients, fertilizer, minerals are in dissolved form reach to the plants through their roots and hence soil moisture measurement is an essential part and the modern technology should enable the agricultural sector to optimize their water usage otherwise the continual withdrawal of water improperly has led to fall in water table at many places leading to drought prone.

Mostly the farmers are illiterate and their affordability to have instruments is limited. Its found that the available soil moisture sensors are rather expensive and not farmers friendly. Hence it is proposed in this paper to design a low cost soil moisture sensor which is both easy to operate by illiterate person and within the reach of poor Indian farmer and their results are presented herewith.

Among the first ${ }^{[4]}$ to investigate the importance of soil moisture and the soil suction in his work and detailed the definition as well as methods of measuring soil water potential or soil suction. Soil suctions are found in all ground that lies above the water table. Recently numerical analysis demonstrated that soil suction may be incorporated into examination of stability for cut slopes and embankments ${ }^{[23,24]}$. The attraction that the soil exerts on to the water is defined as soil suction and manifests as tensile hydraulic stress in a saturated piezometer with a porous filter placed into the intimate contact with water in the soil. The magnitude of an attractive force that the water table exerts on water in the soil is due to the size of the voids in a manner similar to the manner that the diameter of a small bore glass tube governs the height to the level to which water will rise in the tube when its immersed into water and hence if the void is smaller, the harder will be to remove water from the void. Suction in the samples can be used to (i) estimate the in situ stresses in fully saturated clays and (ii) to detect the presence of desiccation in a soil profile. The various methods by which the suction measurement can be used for these purposes are described in detail ${ }^{[5,7]}$.

Irrigation scheduling is generally carried out based on past experience ${ }^{[10]}$ and its well known fact that the farmers and vegetable growers over irrigate to fully satisfy themselves that the water is not a limiting factor for the yield. The scientifically time based irrigation scheduling methods, which are most suitable for vegetable production are the FAO method of estimating crop water requirements ${ }^{[1]}$ and soil moisture sensor. As the differential variable nature of vegetable production through differences in farm management crop varieties and soil type, the FAO method can at be considered as only general guidelines. Soil moisture sensors enable it possible to irrigate in accordance with the unique characteristics of a given crop in a given field. These sensors may be used as a stand alone method or combined with FAO method to optimize the irrigation management based on experience.

Soil moisture sensors are there to measure either soil water matric potential(SMP) or volumetric soil water content(SWC) while tensiometer are probably the commonly used SMP sensor on commercial farms granular matrix sensors are widely present with lots of favorable technical characteristics for on farm use ${ }^{[22]}$.

A wide variety of dielectric sensors using time domain reflectometry (TDR) ${ }^{[14,21]}$ or capacitance technique, also referred as frequency domain reflectometry (FDR) techniques ${ }^{[9,16,2]}$ are available for the on farm measurement of SWC with multiple depth capacitance sensor ${ }^{[0,17]}$ possibly being the commonly used for on farm applications. Tensiometer granular matrix sensor and capacitance sensors can be either read manually as well as automatically to control irrigation systems. Critical is to the use of both SMP and SWC soil moisture sensor is the 
threshold or lower limit value which indicates the degree to the extent to which soil can dry before the irrigation is needed. However the threshold values selected to ensure that crops do not experience water stress or subsequent production yield loss. SMP threshold values are recommended by extension services consultants or instrument suppliers and are mostly on the past experience and a limited number of published scientific studies.

Most of the published SMP threshold values for vegetable species are originate out of agronomic studies comprising yields from treatments with different SMP values $^{[3,27]}$ as most of the studies are conducted on open field crops for specific species and show a wide range of SMP, threshold values suggesting that site specific factors were influential. For fresh tomato reported SMP threshold limits -10 kPA in a fine sandy soil ${ }^{[27]},-20 \mathrm{kPA}$ in a clay loam soil ${ }^{[3]},-30 \mathrm{kPA}$ for loamy soil ${ }^{[2]}$ as well -60 to $-150 \mathrm{kPa}^{[31]}$ and for pepper reported SMPs are $-25 \mathrm{kPa}^{[2,28]}$ as well -45 to $65 \mathrm{kPa}^{[12]}$. The available soil water content (AWC) concept provides an ideal framework for using SWC data for the irrigation management. Threshold values of AWC had been estimated for many species and are listed in FAO manuals as allowable depletion factors ${ }^{[1,8,18]}$. The recommended FAO threshold values for AWC are $70 \%$ for bell pepper, $60 \%$ for Tomato and melon under the conditions of medium evaporative demand ${ }^{[1]}$ with a overall reduction of about $20 \%$ AWC for conditions of low evaporative demand.

The occurrence of sizeable difference between laboratory and field estimated values of $\mathrm{FC}$ and PWP and AWC is established ${ }^{[11,25]}$, the determination of FC and PWP in the laboratory involves considerable soil disturbance however the field determination of FC and PWP is more often due to cropping situations.

The present work pertains to the drip irrigation system $^{[11,25]}$ which is prevalent in intensive vegetable production and the location of soil moisture sensors in relation to both the dripper and plant will have influence on the actual SMP or SWC values and concluded that there are demonstrated uncertainties regarding the use of recommended fixed AWC threshold values based irrigation management on account of the effect on measured AWC values (i) the depth of soil used to estimate AWC (ii) the method used to measure FC and PWP. There are enough possibilities of appreciable errors associated in the measurement of SWC using soil moisture sensors for irrigation management in commercial farms.
Another approach is to use information on soil water dynamics obtained from the continuously measured data's of SWC to estimate insitu SWC threshold values for individual crops and fields. As such this approach will avoid uncertainties associated with applying recommended fixed threshold values that have been obtained from FAO guidelines and elsewhere. As such there are no published studies that assess such approach and the use of SMP threshold values for irrigation management seems to be a straight forward method, however the effectiveness of sensor performance that limit the practical application of these sensors.

The limited working range of tensiometer ( 0 to$80 \mathrm{kPa}$ ) is a limiting factor for crops in rapidly drying soil. Granular matrix sensors overcome the shortcomings of tensiometer but their calibration is tedious and their response is slower in rapidly drying soil ${ }^{[22]}$. The current state of soil moisture sensors for irrigation management seems that SWC sensors for recommended threshold AWC values have difficulties in application but SMP sensors can be readily used with recommended threshold values but there are technical issues that influence their suitability for on farm use.

The most common method for estimating the drained upper limit and lower limit is to extract the water from either disturbed or undisturbed soil sample with the help of soil water extraction device ${ }^{[20]}$ as lower limit is estimated at a SMP of $-1500 \mathrm{kPa}^{[20]}$ and the water content at a matric potential of $-33 \mathrm{kPa}$ is an estimate of drained limit for coarse and fine texture soils, whereas $-10 \mathrm{kPa}$ for coarse textured soils ${ }^{[6,13]}$. Field or laboratory estimation of relationship between soil water content and soil water potential is a costly, difficult as well impractical ${ }^{[26]}$.

In his studies ${ }^{[19]}$ compared the field and laboratory measurements of the lower limit and the drained upper limit and concluded the laboratory estimation of the drained upper limit obtained at a water content corresponding to $-33 \mathrm{kPa}$ were comparatively less than field measured drained upper limits for sands, sandy loams, sandy clay loams and much greater than field estimates for silt loams, silty clay loams and silty clays. Laboratory estimates of the lower limit corresponding to $1500 \mathrm{kPa}$ were comparatively less than field lower limit measurements for sands, silt loams and sandy clay loams and much higher than the field observations for loams, silty clays and clays.

The dielectric constant $\mathrm{E}$ of a free water at frequencies lower than $1000 \mathrm{MHz}$ is $80^{[30]}$ and for dry soil its 
4 hence measurement of the dielectric constant offers a means for soil moisture estimation. Earlier experiments performed at lower order frequencies of $\mathrm{KHz}$ range and found out the importance of interfacial polarization effects in heterogeneous materials such as moist soil. The relaxation frequency of dipoles associated with interfacial polarization is $27 \mathrm{MHz}$.

Fringing capacitance based soil moisture sensor to find the increase in dielectric constant of a soil water mixture with change in water content. The capacitance of root or soil system changes when the contact surface area between roots and the soil increases with growth ${ }^{[15]}$. Usually the capacitance measurements are carried out using a pair of electrodes but the short coming of the electrode pair measurement technique is that the system short circuits in water continuous dispersions and hence a new technique is presented which is based on the measurement of capacitance by utilizing the effect the dielectric constant has on the frequency of an oscillator and its observed that while the presence of gas adjacent to the capacitor plate, no reduction in frequency is noticed but if pure water is present by the side of capacitor plate a much larger reduction in frequency is observed as detailed [33].

The user friendly capacitance sensor capable to be used by unskilled farmer can be handled with much ease and comfort and can be tuned for any crop viz.. Wheat, Rice and optimizing the irrigation by automatic triggering process of water pump, thereby to save resulting excess pumping out of ground water resulting in depletion of precious ground water, water logging, salination of soil, wastage of electricity and soil health deterioration.

Farmers being mostly illiterate, they through their experience follow the "the feel and appearance method" as an easy way of irrigating their fields. It is adopted as way of monitoring soil moisture to determine when to irrigate and how much water to apply. But disadvantage of this method is that the feel and appearance of soil vary with texture and moisture content and at various depths soil has to be digged at 1 foot increments to the root depth of the crop at 3 or more sites per field and sufficient quantity of soil has to be removed to do it. The resulting site destruction cannot be set right and in the same place again soil sample cannot be taken for and it is necessary to vary the sample sites and depths as per the crop, field size, soil texture, and soil stratification.

Predominately farmers of developing countries are illiterate and have no idea of the actual requirement of water for various crops resulting in excess pumping out of ground water thereby depletion of precious ground water apart from excessive watering leads to water logging the fields, excessive runoff and deep percolation leading to valuable water is being lost along with loss of nutrients and chemicals. As farmers use fertilizer in their field as well as various types of pesticides and in the presence of excessive water, these chemical compounds are get carried away leading to salination of soil thereby making the soil infertile as well as soil health deterioration and water logging. And in the process making it unsuitable for future cropping purposes. The huge wastage of electricity as its highly subsidized deteriorates the fiscal health of the various states and Union Government.

\section{EXPERIMENTAL SET-UP}

\section{A. SensorDesign}

Using Pro e 2.0 software, sensor has been designed as depicted below and fabricated using low cost mild steel and tested with an impedance measuring system from $100 \mathrm{~Hz}$ to $110 \mathrm{MHz}$ and circuit measurements are being carried out to identify most optimum frequency of triggering the circuit. The sensor has given highly satisfactory results even at $100 \mathrm{~Hz}$ thereby making the circuit simpler and low cost device suitable for use by Indian farmers and highly viable for field application. Field testing with increasing water application at different frequencies has resulted in satisfactory soil moisture measurements. The experiments were performed under laboratory conditions with north Indian alluvial soil from wheat sown field.

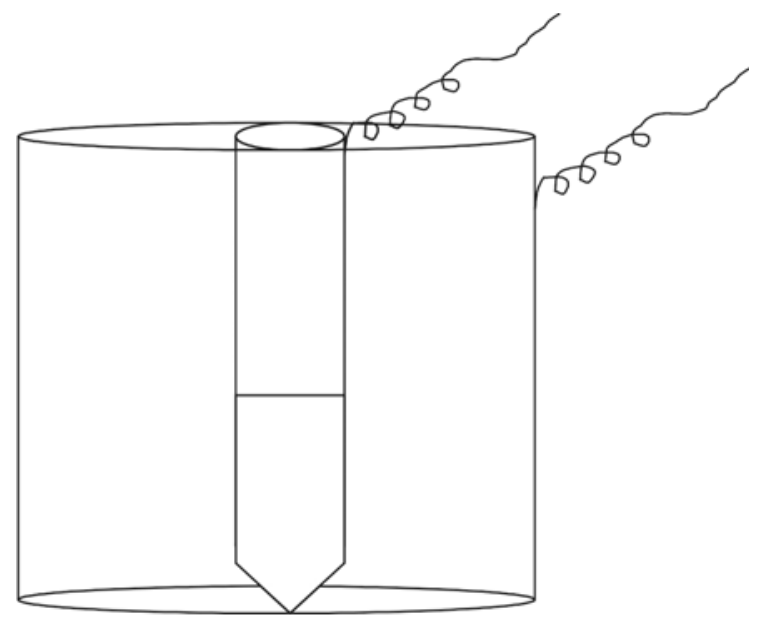

Fig. 1. Topology of the Sensor 

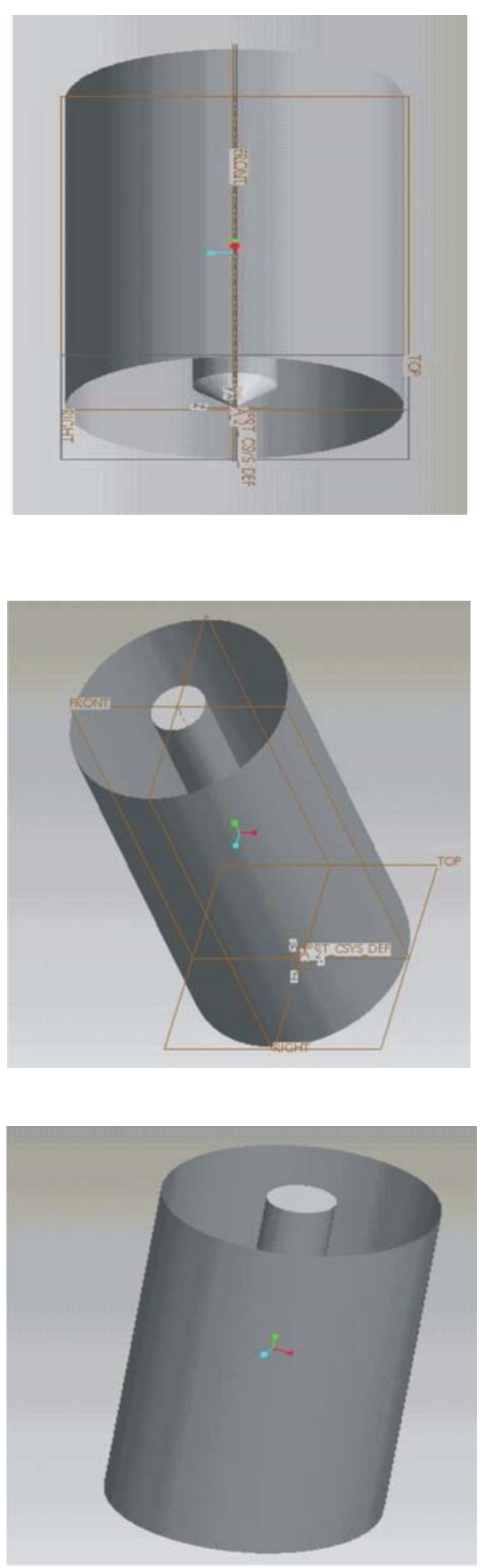

Fig 2. Soil Moisture sensor directional views

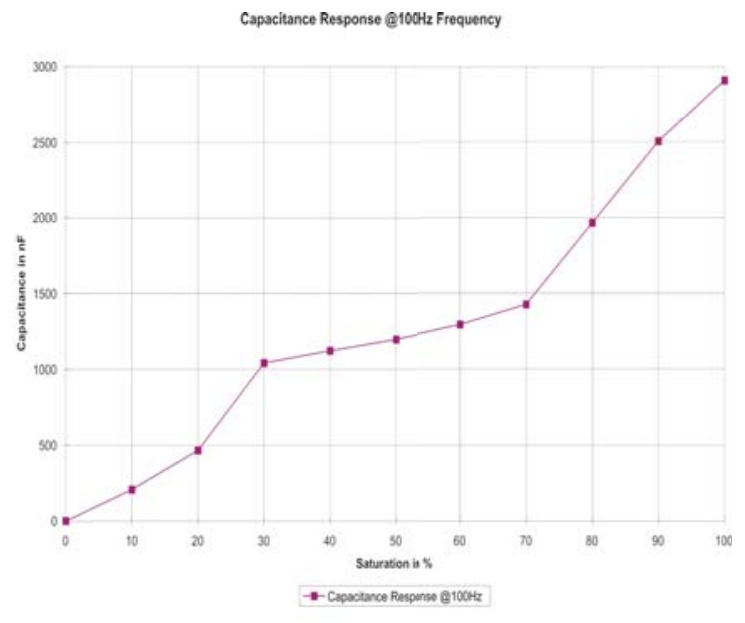

Fig. 3. Sensor output Response

\section{B. Results and conclusions}

The capacitance response characteristics make, it possible to maintain soil moisture at the desired level as per the crop requirement and its withstanding capacity from its field capacity level. Due to plant uptake, evapotranspiration, atmospheric temperature, the soil moisture continue to vary and most of the crops can give a better yield at up to $50 \%$ decrease in soil moisture content from its field capacity. So in this experiment an effort has been made to use a sensor to estimate the PWP and FC and a comparative study is made using tensiometer concurrently and its being concluded that it may provide a new insight to irrigation automation and will be a boon to unskilled farmers to optimize their crop yield as well as saving water, electricity apart from reducing GHGs emission from agricultural fields which takes place upon full saturation.

\section{REFERENCES}

[1] R.G.Allen, L.S.Pereira, D.Raes, M.Smith, 1998, Crop evapotranspiration. Guidelines for computing crop water requirements, FAO Irrigation and Drainage Paper 56, FAO, Rome.

[2] F.R.Beese, Horton and P.J. Wierenga, 1982.Growth and yield response of chile pepper to trickle irrigation, Agron. J. 74 , 1982, pp. 556-561. 
[3] C.A. Bower, B.A. Kratky and N. Ikeda,1975, Growth of tomato on a tropical soil under plastic cover as influenced by irrigation practice and soil salinity, J. Am. Soc. Hort. Sci. 100 pp. 519-521

[4] E.Buckingham, 1907, Studies on the movement of soil moisture.US DeptAgr. Bur. Soils Bulletin 38.

[5] R.J.Chandler, M.S. Crilly, \& C.Montgomery Smith, C. 1992a, A low cost method of assessing clay desiccation for low-rise buildings. Proc. Inst. Civ. Engrs, 92, May, pp.82-89.

[6] E.A.Colman, 1947, A laboratory procedure for determining the field capacity of field soils, Soil Sci 63,pp. 277-283

[7] M.S.Crilly, 2001, 'Estimation of in situ stresses using anisotropic elasticity and suction measurements'. Geotechnique 51, No. 4, pp.383-384

[8] J.Doorenbos, A.H. Kassam, 1979, Yield response to water. FAO Irrigation and Drainage Paper 33, FAO, Rome.

[9] A.Fares, V.Polyakov, 2006, Advances in crop water management using capacitance sensors. Adv. Agron. 90, pp.43-77.

[10] E.Fereres, D.A.Goldhamer, L.R. Parsons, 2003 Irrigation water management of horticultural crops. HortScience 38, pp.1036-1042.

[11] J.Girona, M.Mata, E.Fereres, D.A.Goldhamer, M. Cohen, 2002,Evapotranspiration and soil water dynamics of peach trees under water deficits. Agric. Water Manage. 54, pp.107-122.

[12] D.M. Hedge,1988 Irrigation and nitrogen requirements of bell pepper (Capsicum annuum L.), Indian J.Agric. Sci. 58, 1988, pp. 668-672.

[13] V.C.Jamison, and Kroth, E.M, 1958, Availble soil moisture storage capacity in relation to textural composition and organic matter content of several Missouri soils. Soil Sci.Soc.Am.Proc 22, pp. 189192

[14] S.B.Jones, D.Or, 2004, Frequency domain analysis for extending time domain reflectometry water content measurement in highly saline soils. Soil Sci. Soc. Am. J. 68 (5), pp.1568-1577.
[15] R.E.Miranda, J.B.Yoder, Wilkerson and L.O. Odhiambo., 2005. An autonomous controller for site-specific management of fixed irrigation systems Computers and Electronics in Agriculture, Volume 48, Issue 3, pp.183-197 F.R.

[16] A. Nadler, Y. Lapid, 1996. An improved capacitance sensor for in situ monitoring of soil moisture. Aust. J. Soil Res. 34 (3), pp.361-368.

[17] I.C.Paltineanu, J.L. Starr, 1997. Real-time soil water dynamics using multisensor capacitance probes: laboratory calibration. Soil Sci. Soc. Am. J. 61, pp.1576-1585.

[18] W.D. Pew and B.R. Gardner, 1983 Effects of irrigation practices on vine growth, yield, and quality of muskmelon, J. Am. Soc. Hort. Sci. 108, 1983, pp. 134-137

[19] L.F.Ratlief, J.T.Ritchie, and D.K.Cassel, 1983.A survey of field measured limits of soil water availability as related to laboratory measured properties. Soil Sci.Soc.Am.J 47, pp. 750-775

[20] L.A.Richards, and L.R.Weaver, 1943.Fifteen atmosphere percentages as related to the permanent wilting percentage. Soil Sci. 56,pp. 331339.

[21] D.A.Robinson, S.B.Jones, J.A.Wraith, D.Or, S.P.Firedmena, 2003. A review of advances in dielectric and electrical conductivity measurements in soils using time domain reflectometry. Vadose Zone J. 2, pp.444-475.

[22] R.B.Thompson, M.Gallardo, T.Agu" era, L.C.Valdez, M.D.Ferna'ndez, 2006. Evaluation of the watermark sensor for use with drip irrigated vegetable crops. Irrig. Sci. 24, pp.185-202.

[23] R.B.Thompson, M.Gallardo, L.C.Valdez, M.D.Ferna'ndez, 2007a. Using plant water status to define soil water thresholds for irrigation management of vegetable crops using soil moisture sensors. Agric. Water Manage. 88, pp.147-158.

[24] R.B.Thompson, M.Gallardo, C.Gime'nez, M.D.Ferna'ndez, 2007b. Identification of irrigation and $\mathrm{N}$ management practices that contribute to nitrate leaching loss from an intensive vegetable production system by use of a comprehensive survey. Agric. Water Manage. 89, pp.261-274. 
[25] V.O.Sadras, S.P.Milroy 1996. Soil-water thresholds for the response of leaf expansion and gas exchange: a review. Field Crops Res.47, pp.253-266.

[26] K.E.Saxton, W.J.Rawls, J.S.Romberger, and R.I.Papendick, 1986.Estimating generalized soilwater characteristics from texture. Soil Sci.Am.J 50 pp. 1031-1036.

[27] A.G. Smajstrla and S.J. Locascio, 1996 Automated drip irrigation scheduling of tomato using tensiometers. In: C.R. Camp, E.J. Sadler and R.E. Yoder, Editors, Evapotranspiration and Irrigation Scheduling. Proceedings of the International Conference on American Society of Agricultural Engineers San Antonio, TX, USA, 1996, pp.845-850.

[28] D.A.Smittle, W.L.Dickens, and J.R.Stansell, 1994.Irrigation regimes affects yield and water use by bell pepper, J. Am. Soc. Hort. Sci. 119 pp.936-939.

[29] J.L.Starr, I.C.Paltineanu, 2002. Capacitance devices. In: Dane, J.H., Topp, G.C. (Eds.), Methods of Soil Analysis. Part 4. SSSA Book Ser. 5. SSSA, Madison, WI, USA, pp. 463-474.

[30] K.A.Sudduth, S.T.Drummond, and N.R.Kitchen, 2001. Accuracy issues in electromagnetic induction sensing of soil electrical conductivity for precision agriculture Computers and Electronics in Agriculture, Volume 31, Issue 3, pp. 239-264
[31] S.A.Taylor, 1965.Managing irrigation water on farm. Trans Am.Soc. Agri. Eng.8, pp.433-436

[32] Q.Wang, W. Klassen, Y. Li, M.Codallo. and A.A.Abdul-Baki,2005. Influence of cover crops and irrigation rates on tomato yields and quality in a subtropical region, Hortscience 40, 2005, pp.2125-2131.

[33] N.Zhang, G. Fan, K.H. Lee, G.J.Kluitenberg, T.M.Loughin, 2004. Simultaneous measurement of soil water content and salinity using a frequency response method. SoilSci.Soc. Am.J.68, pp.1515-1525.

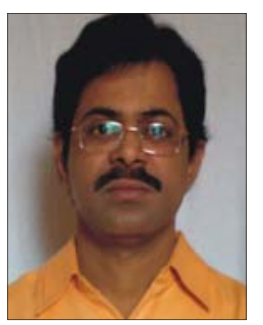

Mr. S. Khaja Syed Shahul Hameed is a Research Scholar at the Indian Institute of Technology, New Delhi and a Post-Graduate in Control \& Instrumentation Engineering from College of Engineering, Guindy. He has over two decades of service in DARE(ICAR), Government of India, CIFRI, Barrackpore and is interested 